Review Article

\title{
Current Status of Sodium Bicarbonate in Coronary Angiography: An Updated Comprehensive Meta-Analysis and Systematic Review
}

\author{
Sadegh Ali-Hassan-Sayegh, ${ }^{1}$ Seyed Jalil Mirhosseini, ${ }^{1}$ Elham Rahimizadeh, \\ Zahra Ghodratipour, ${ }^{1}$ Zahra Sarrafan-Chaharsoughi, ${ }^{1}$ Ali Mohammad Dehghan, ${ }^{1}$ \\ Mohammad Reza Lotfaliani, ${ }^{1}$ Mohammad Rezaeisadrabadi, ${ }^{1}$ Elham Kayvanpour, ${ }^{2}$ \\ Farbod Sedaghat-Hamedani, ${ }^{2}$ Mohamed Zeriouh, ${ }^{3}$ Alexander Weymann, ${ }^{3}$ \\ Anton Sabashnikov, ${ }^{3}$ and Aron-Frederik Popov ${ }^{3}$ \\ ${ }^{1}$ Cardiovascular Research Center, Shahid Sadoughi University of Medical Sciences, Yazd, Iran \\ ${ }^{2}$ Department of Medicine III, University of Heidelberg, Heidelberg, Germany \\ ${ }^{3}$ Department of Cardiothoracic Transplantation and Mechanical Circulatory Support, \\ Royal Brompton \& Harefield NHS Foundation Trust, London, UK
}

Correspondence should be addressed to Sadegh Ali-Hassan-Sayegh; s.alihassan.cardiosurg@gmail.com

Received 4 November 2014; Accepted 25 March 2015

Academic Editor: Frans Leenen

Copyright (C) 2015 Sadegh Ali-Hassan-Sayegh et al. This is an open access article distributed under the Creative Commons Attribution License, which permits unrestricted use, distribution, and reproduction in any medium, provided the original work is properly cited.

\begin{abstract}
This systematic review with meta-analysis sought to determine comparison of efficacy and safety of hydration with sodium bicarbonate versus sodium chloride on contrast induced nephropathy and clinical outcomes. We searched major electronic databases for studies in randomized controlled trials. A value of $P<0.1$ for Q test or $I^{2}>50 \%$ indicated significant heterogeneity between the studies. Literature search of all databases retrieved 650 studies. 29 studies enrolled in meta-analysis. Pooled analysis indicated about the incidence of CIN (OR of 0.718 ; 95\% CI: 0.60 to $0.85 ; P=0.000$ ), requirement of hemodialysis (OR of 1.00 ; 95\% CI: 0.49 to $2.01 ; P=0.9$ ), mean changes of serum creatinine (WMD of 2.321; $95 \%$ CI: 1.995 to $2.648 ; P=0.000$ ), length of hospital stays (WMD of $-0.774 ; 95 \% \mathrm{CI}:-1.65$ to $0.10 ; P=0.08)$, major adverse cardiovascular events $(\mathrm{OR}=1.075,95 \% \mathrm{CI}$ : 0.59 to $1.95 ; P=0.8$ ), and mortality (OR of $0.73 ; 95 \% \mathrm{CI}$ : 0.42 to $1.26 ; P=0.2$ ). Overall, hydration with sodium bicarbonate could significantly reduce CIN and the length of hospital stay compared to sodium chloride. In addition NAC added as a supplement to sodium bicarbonate could increase prophylactic effects against nephropathy.
\end{abstract}

\section{Introduction}

The contrast-induced nephropathy (CIN) is the third most common cause of acute renal failure (ARF) worsening in preexisting renal function impairment that has been associated with morbidity, mortality, and prolonged hospitalization as well as increase in therapy costs $[1,2]$. Diagnosis of CIN is based upon acute impairment of renal function reflected by an absolute increase in the serum creatinine concentration of $0.5 \mathrm{mg} / \mathrm{dL}$ or by relative elevation as $>25 \%$ of baseline within 2 days of contrast exposure [3,4]. Chronic renal failure, diabetic mellitus, contrast media volume, and recurrent administration are considered impairment risk factors $[3,4]$. The pathogenesis of CIN involves a combination of insults affecting renal tubular endothelial cells such as intrarenal vasoconstriction and ischemia, reperfusion injury, and toxicity of renal cells [5]. Currently, the standard of care in the management of patients who require coronary diagnostic imaging is enough hydration, minimizing the volume of contrast agent, and careful use of nephrotoxic drugs $[6,7]$. Hydration could not only increase renal blood flow and reduce renal vasoconstriction, generation of renal 
vasoconstrictor substance and renal medullary ischemia but also directly reduce the toxicity of contrast agent and incidence of CIN [8]. Recently, studies have begun to evaluate whether volume supplementation with sodium bicarbonate may be superior to volume supplementation with sodium chloride $0.9 \%[9,10]$. Sodium bicarbonate can decrease the formation of reactive free oxygen radicals by increasing $\mathrm{pH}$ and producing renal protective markers $[9,10]$. The ideal hydration regimen for preventing CIN remains undefined.

This systematic review with meta-analysis sought to determine the strength of evidence for comparison of effects of sodium bicarbonate versus sodium chloride on incidence of CIN, requirement of hemodialysis, level of serum creatinine, and mortality after coronary angiography.

\section{Methods and Materials}

2.1. Literature Search. A comprehensive literature search was conducted in major electronic databases (Medline/Pubmed, Embase, Elsevier, Web of Knowledge, Sciences online database, and Google Scholar) from their inception through August 16, 2014, to identify RCTs that reported comparison of effects of sodium bicarbonate versus sodium chloride on incidence of CIN, requirement of hemodialysis, heart failure, mortality, duration of hospital stay, and levels of serum creatinine, sodium bicarbonate, and potassium. Predefined search terms included "sodium bicarbonate" and "sodium chloride" and "contrast-induced nephropathy," "CIN," "serum creatinine," "coronary angiography," and "coronary imaging." No language restrictions were applied. All retrieved references of the included RCTs were also reviewed to determine additional studies not indexed in common databases. Studies were included into the analysis when they met the following criteria: (1) RCT, (2) comparison of hydration of sodium bicarbonate with a control group, and [4] reporting data on the incidence of radiocontrast-induced complications according to our review-checklist. Congress presentation and abstracts without peer-reviewed publications of manuscripts were not included in this review.

2.2. Data Extraction and Outcome Measures. Two investigators (Sadegh Ali-Hassan-Sayegh, Elham Rahimizadeh) extracted the data independently, and discrepancies were resolved via a consensus standardized abstraction checklist used for recording data in each study. Data retrieved from the trials included author's name, type of radiocontrast (low-, iso-, or high-osmolality), details of hydration regimens, mean baseline serum creatinine, study design, sample size, mean age, and gender. The incidence of CIN, requirement of hemodialysis, incidence of heart failure and mortality, duration of hospital stay, and levels of serum creatinine, sodium bicarbonate, and potassium were recorded for each group. For exploration of heterogeneity among trials, subgroup analysis of disparities in the patients' characteristics was performed for (1) average age ( $<65$ versus $\geq 65$ years), ( 2 ) diabetes ( $\leq 30$ versus $>30 \%$ ), (3) radiocontrast (low, iso), and (4) procedure (elective versus emergency).
2.3. Definitions. CIN is defined as $\geq 25 \%, \geq 0.5 \mathrm{mg} / \mathrm{dL}, \geq 25 \%$, and $\geq 0.5 \mathrm{mg} / \mathrm{dL}$ increase in creatinine from baseline and renal failure is defined as new onset of hemodialysis.

2.4. Statistical Analysis, Publication Bias, and Quality Assessment. Data were analyzed by STATA version 11.0 utilizing METAN and METABIAS modules. The effect sizes measured were odds ratio (OR) with $95 \%$ confidence interval (CI) for categorical variable. For noncategorical data the weighted mean difference (WMD) with 95\% CI was used for calculating differences in serum creatinine, sodium bicarbonate, and potassium and length of hospital stay between sodium bicarbonate and sodium chloride groups. OR $<1$ favored sodium bicarbonate and $\mathrm{OR}>1$ favored sodium chloride. RCTs with no events in the 2 arms were discarded from pooled analysis. Forest plots were created for each outcome. A value of $P<0.1$ for $Q$ test or $I^{2}>50 \%$ indicated significant heterogeneity among the studies. Heterogeneity among trials was accounted for by applying a random effect model when indicated. The presence of publication bias was evaluated using the Begg and Egger tests. Quality assessment of RCTs was performed by using the Jadad score. The Jadad score assesses 3 items including randomization (0-2 points), blinding of study ( $0-2$ points), and withdrawals and dropouts (0-1 points). Higher scores indicate better reporting ("high" quality: 5; "good" quality: 3-4; "poor" quality: 0-2). Results were considered statistically significant at a $P$ value less than 0.05 .

\section{Results}

3.1. Literature Search Strategy and Included Trials. Literature search retrieved 650 studies from screened databases of which $400(61.5 \%)$ were excluded after initial review (Figure 1). Of 250 primary included studies, 221 were excluded after detailed evaluation due to insufficient reporting of endpoints of interest. The final analysis included 29 RCTs.

\subsection{Study Characteristics and Effect Measures}

(Sodium Bicarbonate versus Sodium Chloride)

3.2.1. Incidence of Contrast-Induced Nephropathy. A total of 5698 patients were included from 28 RCTs reported data about effects of hydration with sodium bicarbonate on incidence of CIN (Table 1). Patient population of RCTs ranged from 34 to 502 patients. From 5698 patients, 2847 cases were allocated to SB and 2851 cases to the SC group. The overall incidence of CIN was $10.03 \%$ ranging from $3.01 \%$ to $23.3 \%$. CIN occurred in $8.57 \%$ in SB group and $11.50 \%$ in SC group (Table 2). Pooled treatment effect analysis revealed that SB versus SC significantly reduced the incidence of CIN with an OR of 0.718 (95\% CI: $0.60-0.85 ; P=0.000)$ using a random model (Figure 1). Significant heterogeneity was observed among the RCTs (chi-squared $=65.79, I^{2}=59.0 \%$ ). Subgroup analysis showed that preventing effects of SB was superior to SC on CIN in patients aged above and below 65 years, diabetic and nondiabetic patients, cases undergoing low-osmolality 


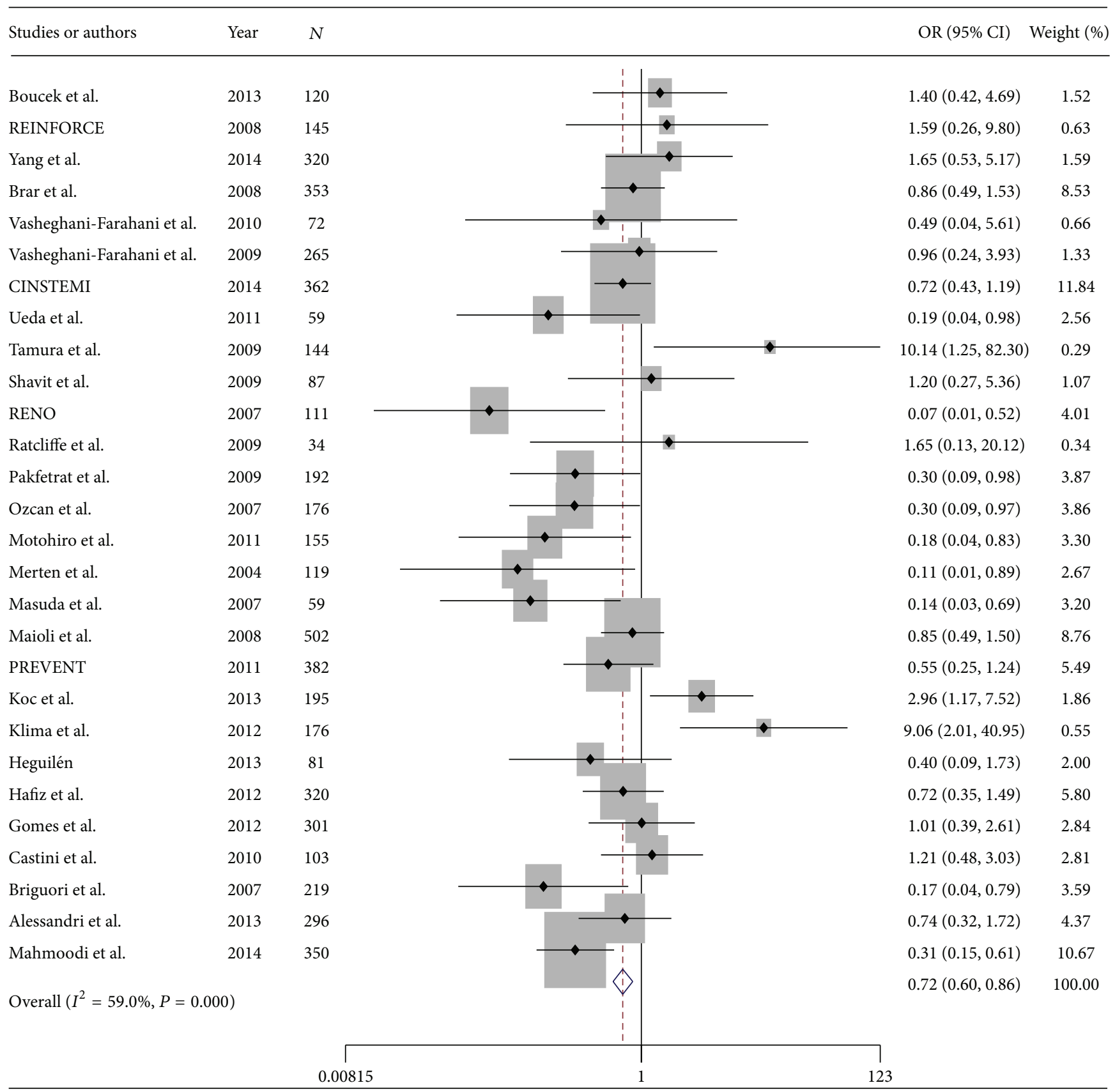

FIGURE 1: Forest plot of odds ratio (OR) for hydration with sodium bicarbonate on contrast-induced nephropathy.

radiocontrast imaging compared to iso-osmolality and cases undergoing emergency angiography compared to elective angiography (Table 3). Begg and Egger tests showed that there was no potential publication bias among the included RCTs (Begg test, $P=0.327$; Egger test, $P=0.327$ ).

3.2.2. Requirement of Hemodialysis. A total of 3765 patients were included from 19 RCTs reporting data on requirement of hemodialysis (Table 1). After removing RCTs with no events in 2 arms, a total of 2267 patients were included from 10 studies enrolled in meta-analysis. From all patients, 1130 cases were allocated to SB and 1137 to the SC group. The overall incidence of requirement of hemodialysis was $1.32 \%$ ranging from $0.3 \%$ to $6.7 \%$. Requirement of hemodialysis occurred in $1.32 \%$ of the cases in SB group and $1.31 \%$ in control group (Table 2). Pooled treatment effect analysis revealed that SB versus SC could not reduce incidence of requirement of hemodialysis after coronary angiography with an OR of 1.00 (95\% CI: $0.49-2.01 ; P=0.9$ ) using a fixed model (Figure 2). No significant heterogeneity was observed among the RCTs (chi-squared $=5.67, I^{2}=0.0 \%$ ).

3.2.3. Mean Changes of Serum Creatinine, Sodium Bicarbonate, and Potassium. From 1267 patients, 636 cases were 


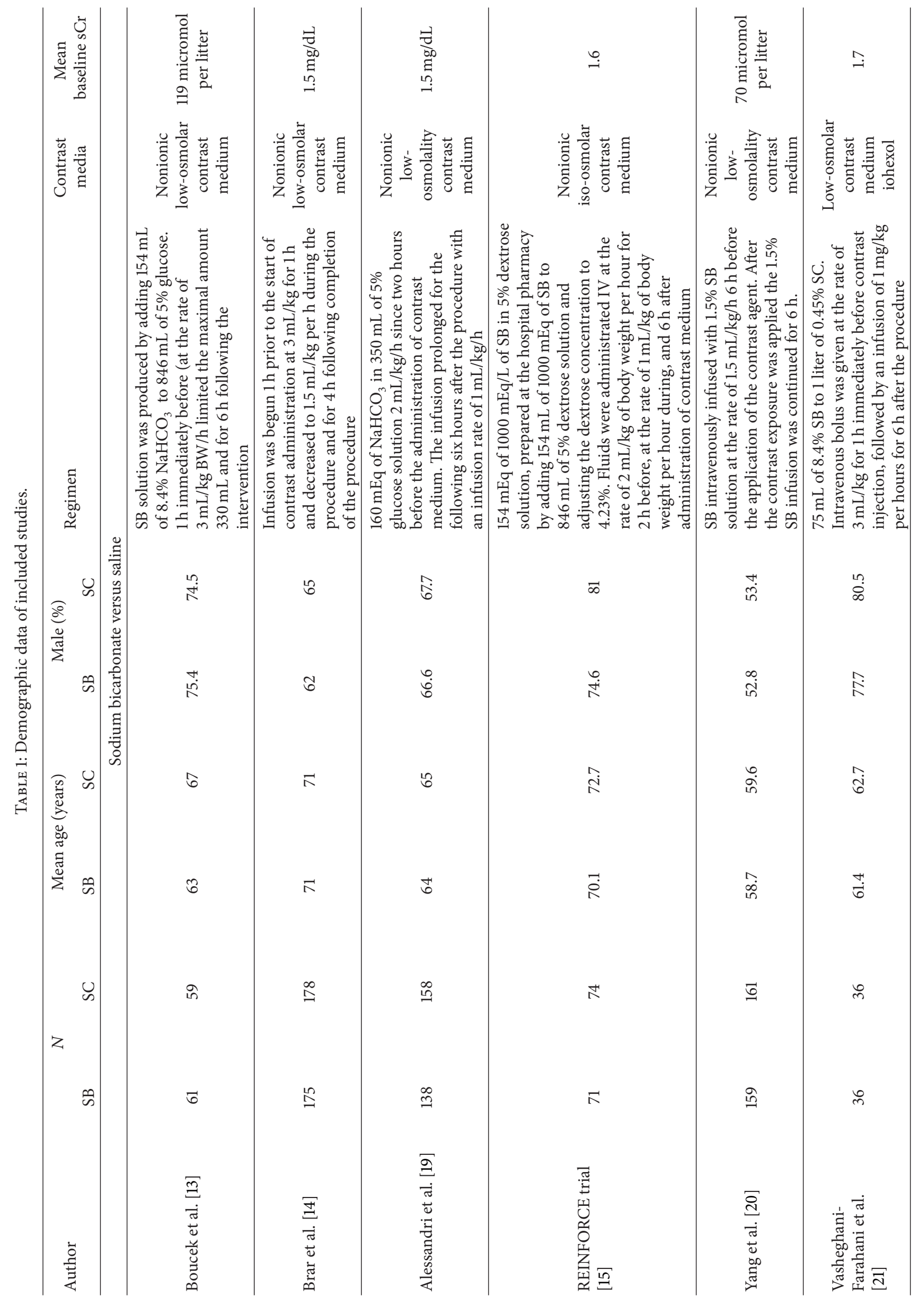




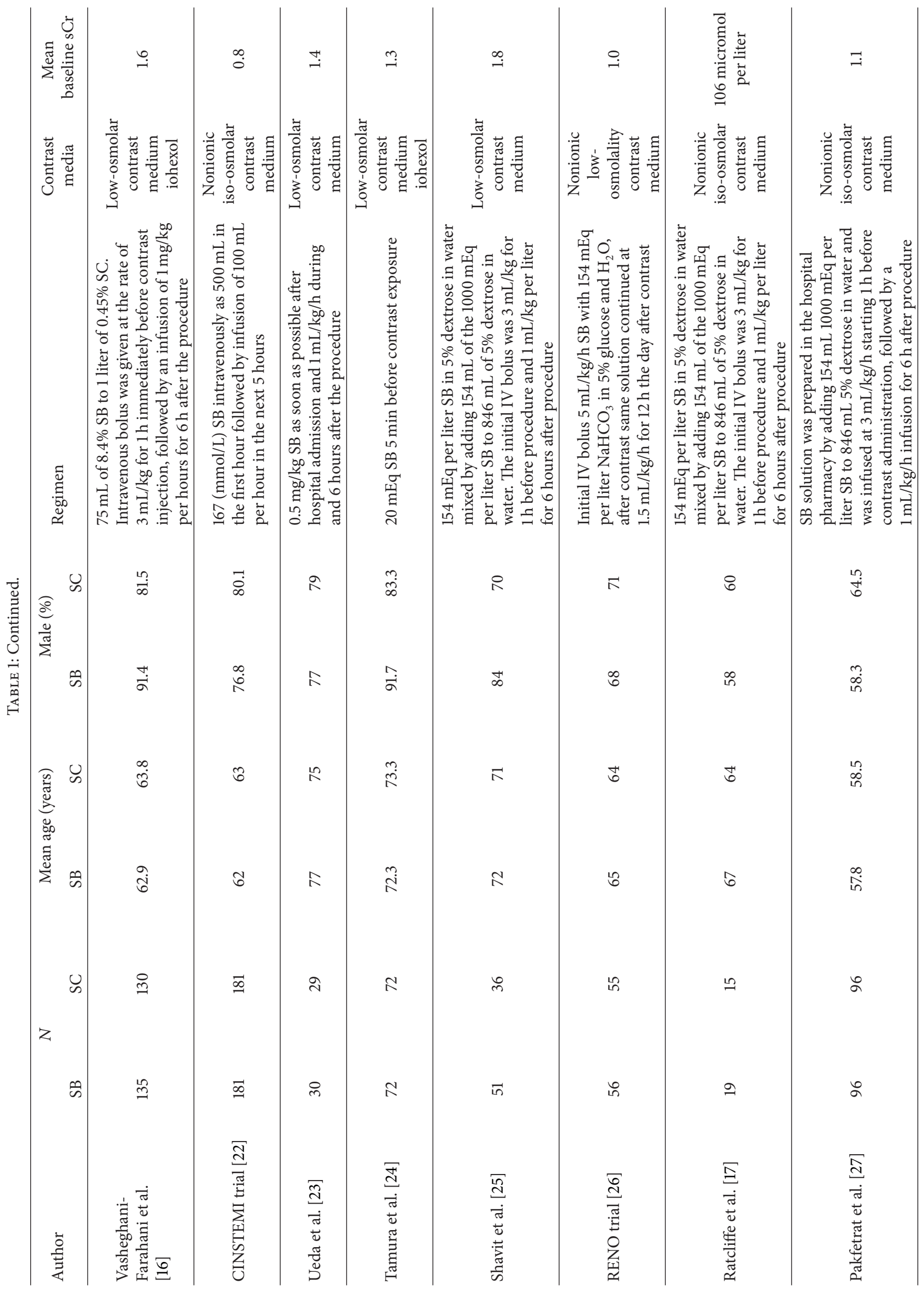




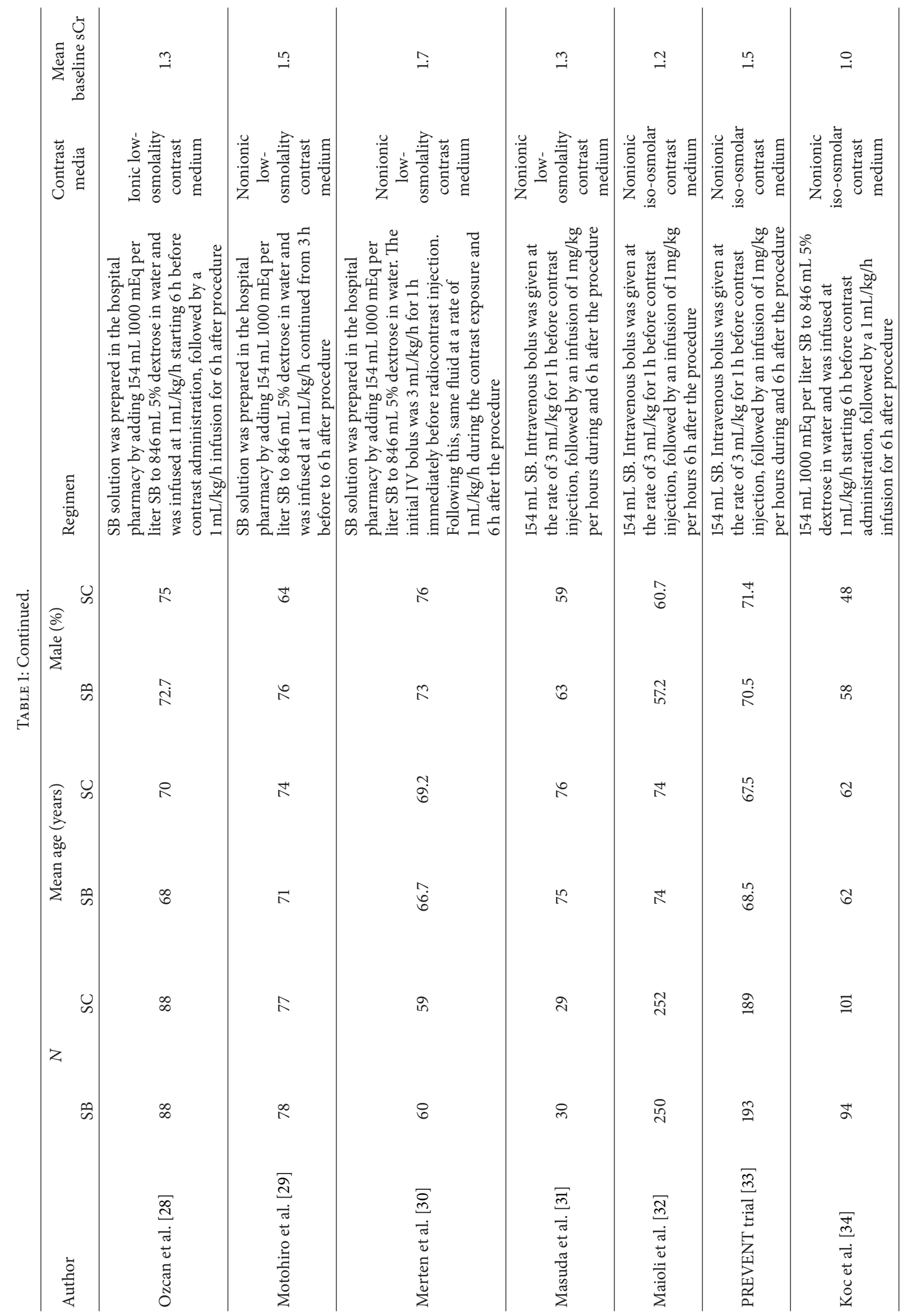




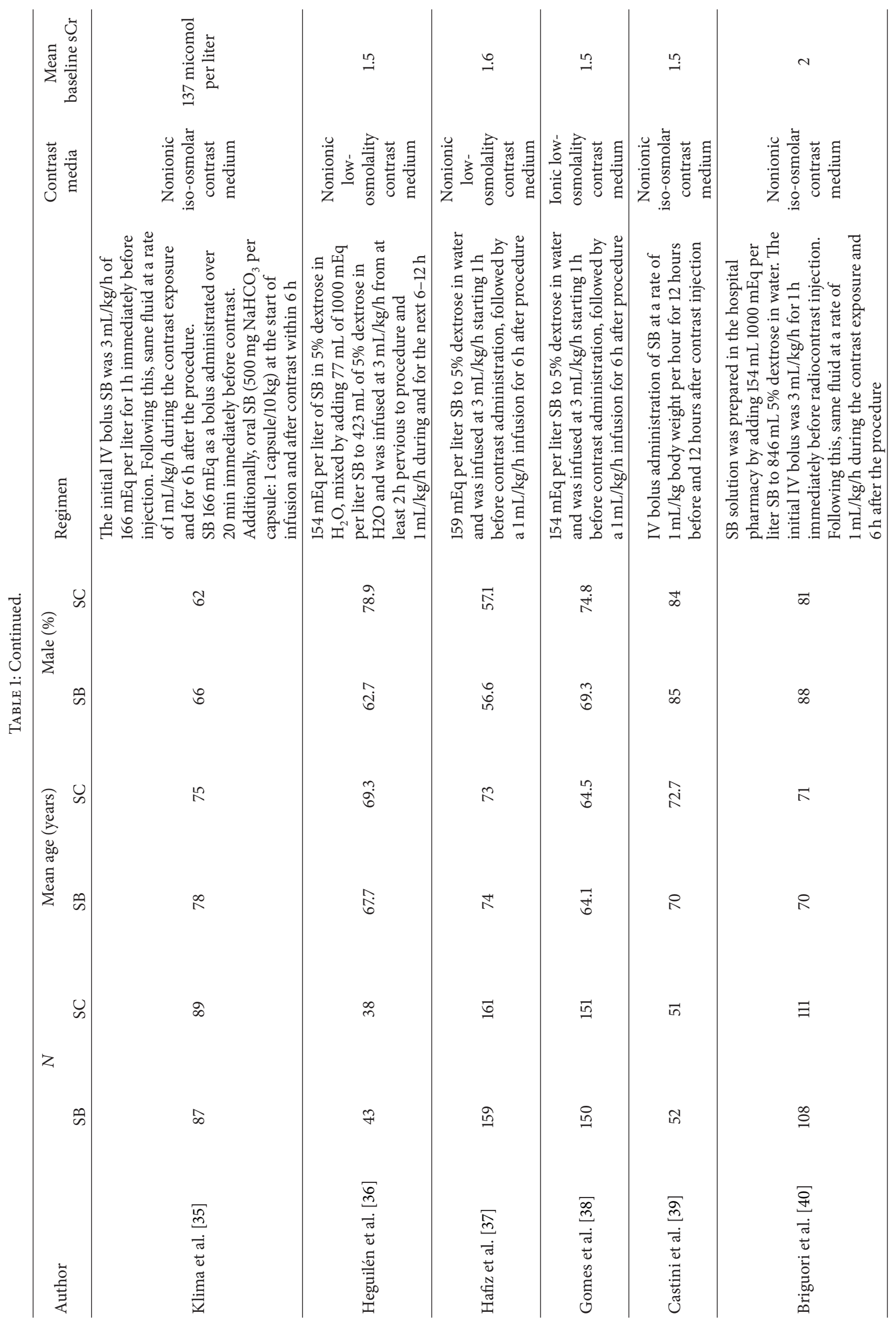




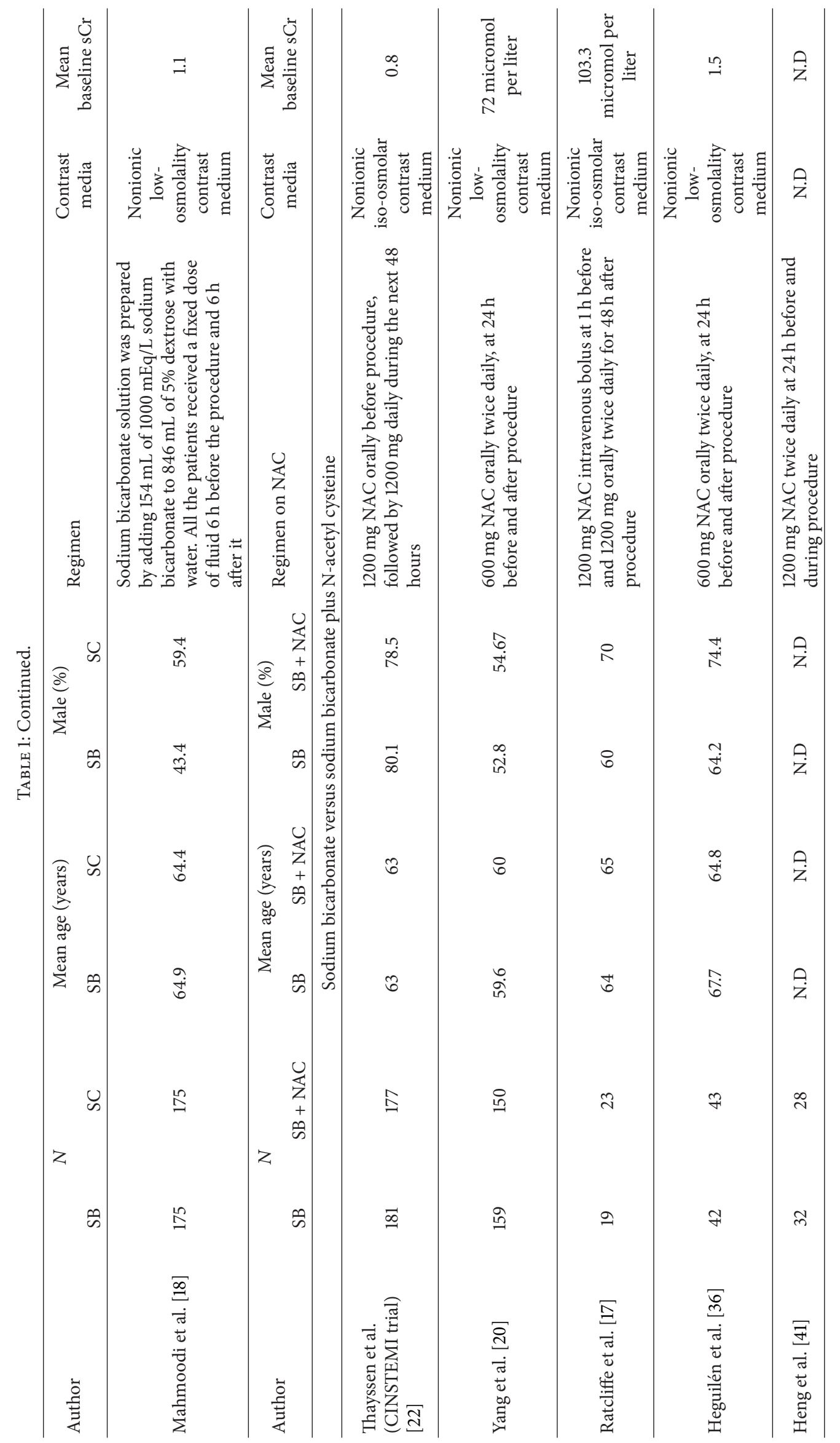


TABLE 2: Clinical outcomes of included studies.

(a)

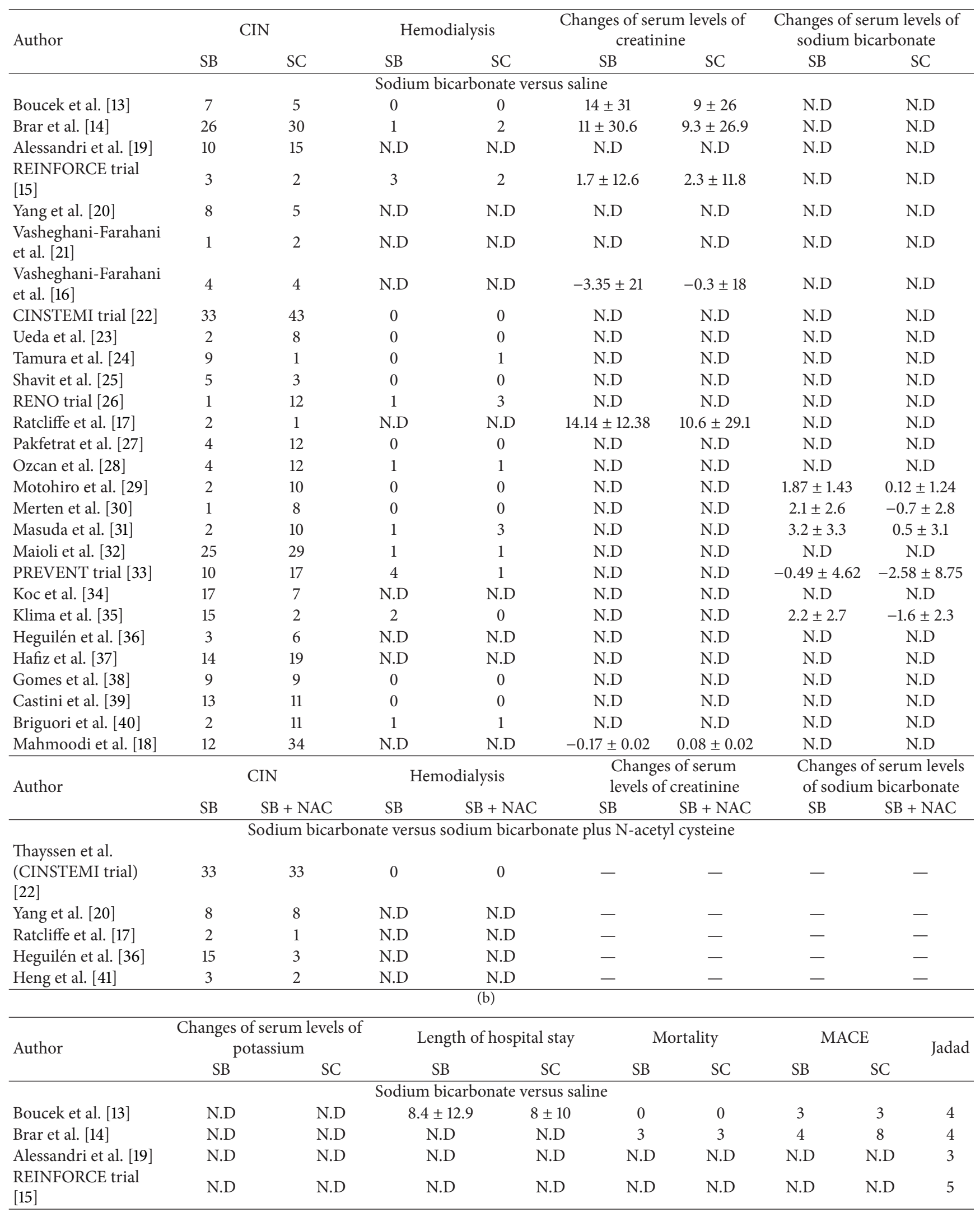


(b) Continued.

\begin{tabular}{|c|c|c|c|c|c|c|c|c|c|}
\hline \multirow[t]{2}{*}{ Author } & \multicolumn{2}{|c|}{$\begin{array}{c}\text { Changes of serum levels of } \\
\text { potassium }\end{array}$} & \multicolumn{2}{|c|}{ Length of hospital stay } & \multicolumn{2}{|c|}{ Mortality } & \multicolumn{2}{|c|}{ MACE } & \multirow[t]{2}{*}{ Jadad } \\
\hline & $\mathrm{SB}$ & SC & SB & SC & SB & SC & SB & SC & \\
\hline Yang et al. [20] & N.D & N.D & N.D & N.D & N.D & N.D & N.D & N.D & 3 \\
\hline $\begin{array}{l}\text { Vasheghani-Farahani } \\
\text { et al. [21] }\end{array}$ & N.D & N.D & $1.5 \pm 5$ & $4.5 \pm 3$ & N.D & N.D & N.D & N.D & 5 \\
\hline $\begin{array}{l}\text { Vasheghani-Farahani } \\
\text { et al. [16] }\end{array}$ & N.D & N.D & $1 \pm 3$ & $1 \pm 6$ & N.D & N.D & N.D & N.D & 5 \\
\hline CINSTEMI trial [22] & N.D & N.D & N.D & N.D & N.D & N.D & N.D & N.D & 3 \\
\hline Ueda et al. [23] & N.D & N.D & $22.8 \pm 17.9$ & $21.4 \pm 19.6$ & 2 & 8 & 9 & 10 & 4 \\
\hline Tamura et al. [24] & N.D & N.D & N.D & N.D & 0 & 0 & 0 & 0 & 3 \\
\hline Shavit et al. [25] & N.D & N.D & N.D & N.D & N.D & N.D & N.D & N.D & 2 \\
\hline RENO trial [26] & N.D & N.D & N.D & N.D & 1 & 4 & N.D & N.D & 2 \\
\hline Ratcliffe et al. [17] & N.D & N.D & N.D & N.D & N.D & N.D & 0 & 0 & 3 \\
\hline Pakfetrat et al. [27] & N.D & N.D & N.D & N.D & 0 & 0 & N.D & N.D & 5 \\
\hline Ozcan et al. [28] & N.D & N.D & N.D & N.D & N.D & N.D & 0 & 0 & 2 \\
\hline Motohiro et al. [29] & $-0.46 \pm 0.61$ & $-0.32 \pm 0.38$ & N.D & N.D & 0 & 0 & 0 & 0 & 3 \\
\hline Merten et al. [30] & $-0.26 \pm 0.48$ & $-0.17 \pm 0.59$ & N.D & N.D & N.D & N.D & N.D & N.D & 3 \\
\hline Masuda et al. [31] & N.D & N.D & N.D & N.D & 0 & 2 & N.D & N.D & 3 \\
\hline Maioli et al. [32] & N.D & N.D & N.D & N.D & 4 & 3 & N.D & N.D & 5 \\
\hline PREVENT trial [33] & $-0.3 \pm 0.58$ & $-0.23 \pm 0.52$ & N.D & N.D & 0 & 1 & 10 & 3 & 5 \\
\hline Koc et al. [34] & N.D & N.D & N.D & N.D & N.D & N.D & N.D & N.D & 2 \\
\hline Klima et al. [35] & N.D & N.D & N.D & N.D & 5 & 4 & N.D & N.D & 4 \\
\hline Heguilén et al. [36] & N.D & N.D & N.D & N.D & N.D & N.D & N.D & N.D & 3 \\
\hline Hafiz et al. [37] & N.D & N.D & N.D & N.D & 0 & 0 & 0 & 0 & 3 \\
\hline Gomes et al. [38] & N.D & N.D & $7.5 \pm 10$ & $8.6 \pm 9.7$ & 7 & 5 & N.D & N.D & 2 \\
\hline Castini et al. [39] & N.D & N.D & N.D & N.D & N.D & N.D & N.D & N.D & 2 \\
\hline Briguori et al. [40] & N.D & N.D & N.D & N.D & N.D & N.D & N.D & N.D & 3 \\
\hline Mahmoodi et al. [18] & N.D & N.D & N.D & N.D & 0 & 0 & N.D & N.D & 2 \\
\hline \multirow[t]{2}{*}{ Author } & \multicolumn{2}{|c|}{$\begin{array}{l}\text { changes of serum } \\
\text { levels of potassium }\end{array}$} & \multicolumn{2}{|c|}{ Length of hospital stay } & \multicolumn{2}{|c|}{ Mortality } & \multicolumn{2}{|c|}{ MACE } & \multirow[t]{2}{*}{ Jadad } \\
\hline & SB & $\mathrm{SB}+\mathrm{NAC}$ & SB & $\mathrm{SB}+\mathrm{NAC}$ & SB & $\mathrm{SB}+\mathrm{NAC}$ & SB & $\mathrm{SB}+\mathrm{NAC}$ & \\
\hline \multicolumn{10}{|c|}{ Sodium bicarbonate versus sodium bicarbonate plus $\mathrm{N}$-acetyl cysteine } \\
\hline $\begin{array}{l}\text { Thayssen et al. } \\
\text { (CINSTEMI trial) } \\
{[22]}\end{array}$ & - & - & - & - & - & - & 6 & 3 & 3 \\
\hline Yang et al. [20] & - & - & - & - & - & - & N.D & N.D & 3 \\
\hline Ratcliffe et al. [17] & - & - & - & - & - & - & 0 & 0 & 3 \\
\hline Heguilén et al. [36] & - & - & - & - & - & - & N.D & N.D & 3 \\
\hline Heng et al. [41] & - & - & - & - & - & - & N.D & N.D & 3 \\
\hline
\end{tabular}

allocated to SB and 631 to the SC group (Table 1). Pooled analysis showed that SB had similar effects on mean serum creatinine with WMD of -0.250 (95\% CI: -0.254 to -0.246 ; $P=0.000$ ) using a fixed model (Figure 3 ). No significant heterogeneity was observed among the RCTs (chi-squared = $\left.3.03, I^{2}=0.0 \%\right)$. Mean level of serum sodium bicarbonate for 5 trials was $0.46 \pm 3.28$ with $1.77 \pm 2.93$ for SB and $-0.85 \pm 3.63$ for the SC group. From 891 patients, 448 cases were allocated to SB and 443 to the SC group (Table 1). Pooled analysis showed that SB versus SC could significantly increase mean level of serum sodium bicarbonate with WMD of $2.321(95 \%$ CI: 1.995 to $2.648 ; P=0.000$ ) using a random model (see Supplemental Figure 1 in Supplementary Material available online at http://dx.doi.org/10.1155/2015/690308). Significant heterogeneity was observed among the RCTs (chi-squared = $23.58, I^{2}=83 \%$ ). A total of 656 patients were included from 3 RCTs reporting data on mean level of serum potassium
(Table 1). Pooled analysis indicated that SB versus SC could significantly decrease mean level of serum potassium with WMD of -0.091 (95\% CI: -0.171 to $-0.011 ; P=0.02$ ) using a fixed model (Supplemental Figure 2).

3.2.4. Length of Hospital Stays (LHS). Mean LHS for 5 trials (817 patients) were $8.47 \pm 9.71$ days with $8.24 \pm 9.76$ for SB and $8.7 \pm 9.66$ for the SC group (Tables 1 and 2). Pooled analysis revealed that SB had a trend towards decreasing LHS with a WMD of -0.774 (95\% CI: -1.65 to $0.10 ; P=0.08$ ) using a random effect model. No Significant heterogeneity was observed among the RCTs (chi-squared $=7.58, I^{2}=$ $47.2 \%)$.

3.2.5. Major Adverse Cardiovascular Events (MACE). After discarding 5 RCTs for having no events in 2 comparative arms, 4 RCTs (914 patients) were included in the analysis. 
TABLE 3: Subgroup analysis for clinical outcomes.

\begin{tabular}{|c|c|c|c|}
\hline Subgroup & Studies $(N)$ & Odd ratio or SMD $(95 \% \mathrm{CI})$ & $P$ value \\
\hline \multicolumn{4}{|c|}{ S.G.A for CIN according to OR } \\
\hline \multicolumn{4}{|l|}{ Age } \\
\hline$\leq 65$ & 11 & $0.770(0.582-1.019)$ & 0.068 \\
\hline$>65$ & 16 & $0.765(0.602-0.973)$ & 0.029 \\
\hline \multicolumn{4}{|l|}{ Diabetic mellitus } \\
\hline$\leq 30$ & 9 & $0.708(0.535-0.937)$ & 0.016 \\
\hline$>30$ & 14 & $0.774(0.581-1.031)$ & 0.080 \\
\hline \multicolumn{4}{|l|}{ Radiocontrast } \\
\hline Iso-osmolality & 9 & $0.902(0.692-1.174)$ & 0.442 \\
\hline Low-osmolality & 18 & $0.663(0.514-0.853)$ & 0.001 \\
\hline \multicolumn{4}{|l|}{ Procedure } \\
\hline Elective & 23 & $0.869(0.710-1.065)$ & 0.176 \\
\hline Emergency & 4 & $0.447(0.290-0.687)$ & 0.000 \\
\hline \multicolumn{4}{|c|}{ S.G.A for hemodialysis according to OR } \\
\hline \multicolumn{4}{|c|}{ 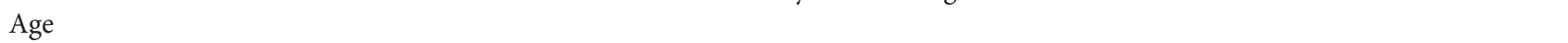 } \\
\hline$\leq 65$ & 2 & $0.486(0.088-2.697)$ & 0.409 \\
\hline$>65$ & 8 & $1.177(0.540-2.564)$ & 0.681 \\
\hline \multicolumn{4}{|l|}{ Diabetic mellitus } \\
\hline$\leq 30$ & 2 & $0.489(0.088-2.702)$ & 0.412 \\
\hline$>30$ & 7 & $0.918(0.387-2.180)$ & 0.847 \\
\hline \multicolumn{4}{|l|}{ Radiocontrast } \\
\hline Iso-osmolality & 4 & $2.459(0.704-8.583)$ & 0.158 \\
\hline Low-osmolality & 6 & $0.594(0.238-1.484)$ & 0.265 \\
\hline \multicolumn{4}{|l|}{ Procedure } \\
\hline Elective & 8 & $1.425(0.629-2.226)$ & 0.396 \\
\hline Emergency & 2 & $0.307(0.060-1.572)$ & 0.156 \\
\hline \multicolumn{4}{|c|}{ S.G.A for mortality according to OR } \\
\hline \multicolumn{4}{|l|}{ Age } \\
\hline$\leq 65$ & 2 & $0.885(0.336-2.331)$ & 0.804 \\
\hline$>65$ & 6 & $0.667(0.341-1.303)$ & 0.236 \\
\hline \multicolumn{4}{|l|}{ Diabetic mellitus } \\
\hline$\leq 30$ & 4 & $0.681(0.339-1.368)$ & 0.280 \\
\hline$>30$ & 3 & $0.902(0.352-2.311)$ & 0.830 \\
\hline \multicolumn{4}{|l|}{ Radiocontrast } \\
\hline Iso-osmolality & 3 & $1.136(0.444-2.906)$ & 0.791 \\
\hline Low-osmolality & 5 & $0.578(0.290-1.151)$ & 0.119 \\
\hline \multicolumn{4}{|l|}{ Procedure } \\
\hline Elective & 5 & $1.202(0.618-2.339)$ & 0.588 \\
\hline Emergency & 3 & $0.199(0.059-0.672)$ & 0.009 \\
\hline \multicolumn{4}{|c|}{ S.G.A for length of hospital stay according to SMD } \\
\hline \multicolumn{4}{|c|}{$x_{0}$} \\
\hline$\leq 65$ & 4 & $-0.104(-0.247$ to 0.039$)$ & 0.153 \\
\hline$>65$ & 1 & $0.075(-0.436$ to 0.585$)$ & 0.774 \\
\hline \multicolumn{4}{|l|}{ Diabetic mellitus } \\
\hline$\leq 30$ & 2 & $-0.240(-0.526$ to 0.047$)$ & 0.101 \\
\hline$>30$ & 3 & $-0.047(-0.204$ to 0.110$)$ & 0.560 \\
\hline \multicolumn{4}{|l|}{ Radiocontrast } \\
\hline Iso-osmolality & All studies were low & All studies were low & All studies were low \\
\hline Low-osmolality & osmolality & osmolality & osmolality \\
\hline \multicolumn{4}{|l|}{ Procedure } \\
\hline Elective & 4 & $-0.104(-0.247$ to 0.039$)$ & 0.153 \\
\hline Emergency & 1 & $0.075(-0.436$ to 0.585$)$ & 0.774 \\
\hline
\end{tabular}


TABLE 3: Continued.

\begin{tabular}{|c|c|c|c|}
\hline Subgroup & Studies $(N)$ & Odd ratio or SMD $(95 \% \mathrm{CI})$ & $P$ value \\
\hline \multicolumn{4}{|c|}{ S.G.A for adverse events according to OR } \\
\hline \multicolumn{4}{|l|}{ Age } \\
\hline$\leq 65$ & 1 & $0966(0.187-4.987)$ & 0.961 \\
\hline$>65$ & 3 & $1.093(0.574-2.081)$ & 0.787 \\
\hline \multicolumn{4}{|l|}{ Diabetic mellitus } \\
\hline$\leq 30$ & 1 & $0.817(0.273-2.431)$ & 0.713 \\
\hline$>30$ & 2 & $0.625(0.238-1.643)$ & 0.340 \\
\hline \multicolumn{4}{|l|}{ Radiocontrast } \\
\hline Iso-osmolality & 1 & $3.388(0.918-12.509)$ & 0.067 \\
\hline Low-osmolality & 3 & $0.701(0.340-1.443)$ & 0.334 \\
\hline \multicolumn{4}{|l|}{ Procedure } \\
\hline Elective & 3 & $1.213(0.590-2.490)$ & 0.601 \\
\hline Emergency & 1 & $0.841(0.273-2.431)$ & 0.713 \\
\hline \multicolumn{4}{|c|}{ S.G.A mean changes of serum creatinine to SMD } \\
\hline \multicolumn{4}{|c|}{ 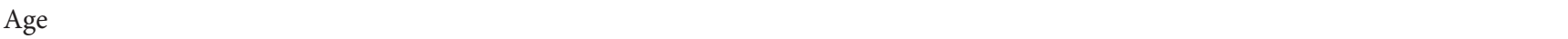 } \\
\hline$\leq 65$ & 2 & $-0.053(-0.253$ to 0.147$)$ & 0.605 \\
\hline$>65$ & 3 & $0.036(-0.134$ to 0.206$)$ & 0.677 \\
\hline \multicolumn{4}{|l|}{ Diabetic mellitus } \\
\hline$\leq 30$ & 1 & $-0.156(-0.397$ to 0.085$)$ & 0.206 \\
\hline$>30$ & 4 & $0.062(-0.092$ to 0.215$)$ & 0.432 \\
\hline \multicolumn{4}{|l|}{ Radiocontrast } \\
\hline Iso-osmolality & 1 & $-0.156(-0.397$ to 0.085$)$ & 0.206 \\
\hline Low-osmolality & 4 & $0.062(-0.092$ to 0.215$)$ & 0.432 \\
\hline \multicolumn{4}{|l|}{ Procedure } \\
\hline Elective & All studies had elective & All studies had elective & All studies had elective \\
\hline Emergency & procedure & procedure & procedure \\
\hline \multicolumn{4}{|c|}{ S.G.A for mean changes of sodium bicarbonate according to SMD } \\
\hline \multicolumn{4}{|c|}{ 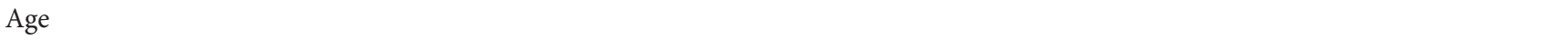 } \\
\hline$\leq 65$ & All studies had age more & All studies had age more & All studies had age more \\
\hline$>65$ & than 65 years & than 65 years & than 65 years \\
\hline \multicolumn{4}{|l|}{ Diabetic mellitus } \\
\hline$\leq 30$ & - & - & - \\
\hline$>30$ & 4 & $1.248(1.058$ to 1.439$)$ & 0.000 \\
\hline \multicolumn{4}{|l|}{ Radiocontrast } \\
\hline Iso-osmolality & 2 & $0.622(0.449$ to 0.795$)$ & 0.000 \\
\hline Low-osmolality & 3 & $1.120(0.889$ to 1.352$)$ & 0.000 \\
\hline \multicolumn{4}{|l|}{ Procedure } \\
\hline Elective & 4 & $0.797(0.654$ to 0.941$)$ & 0.000 \\
\hline Emergency & 1 & $0.843(0.310$ to 1.376$)$ & 0.002 \\
\hline
\end{tabular}

Major adverse cardiovascular events occurred in 5.66\% of the cases in SB group and $5.27 \%$ in SC group (Tables 1 and 2). Pooled treatment effect analysis demonstrated that incidence of MACE is similar in SB and SC groups (OR $=1.075,95 \%$ CI: $0.59-1.95 ; P=0.8$, and chi-squared $=4.77, I^{2}=37.1 \%$ ) (Supplemental Figure 3).

3.2.6. Mortality. After discarding 7 RCTs because of no death event in 2 comparative arms, 8 RCTs were used for the metaanalysis. Mortality occurred in $2.26 \%$ in SB and $3.08 \%$ in SC group (Tables 1 and 2). Pooled treatment effect analysis showed that SB versus SC could not significantly reduce incidence of mortality with an OR of 0.73 (95\% CI: 0.42-1.26; $P=0.2)$ using a fixed model. No significant heterogeneity was observed among the RCTs (chi-squared $=7.43, I^{2}=$ 5.8\%) (Supplemental Figure 4).

\subsection{Sodium Bicarbonate versus Sodium Bicarbonate Plus Anti- Oxidant Agent (N-Acetyl Cysteine)}

3.3.1. Incidence of Contrast-Induced Nephropathy. A total of 5 RCTs (854 patients) were used for the analysis. Patient population of the RCTs ranged from 42 to 358 patients. From 854 patients, 433 cases were allocated to SB alone and 421 to the SB plus NAC group. The overall incidence of CIN was $12.67 \%$ ranging from $5.17 \%$ to $21.17 \%$. CIN occurred in $14.08 \%$ in SB alone and $11.16 \%$ in SB plus NAC group. Pooled treatment effect analysis revealed that SB plus NAC versus SB 


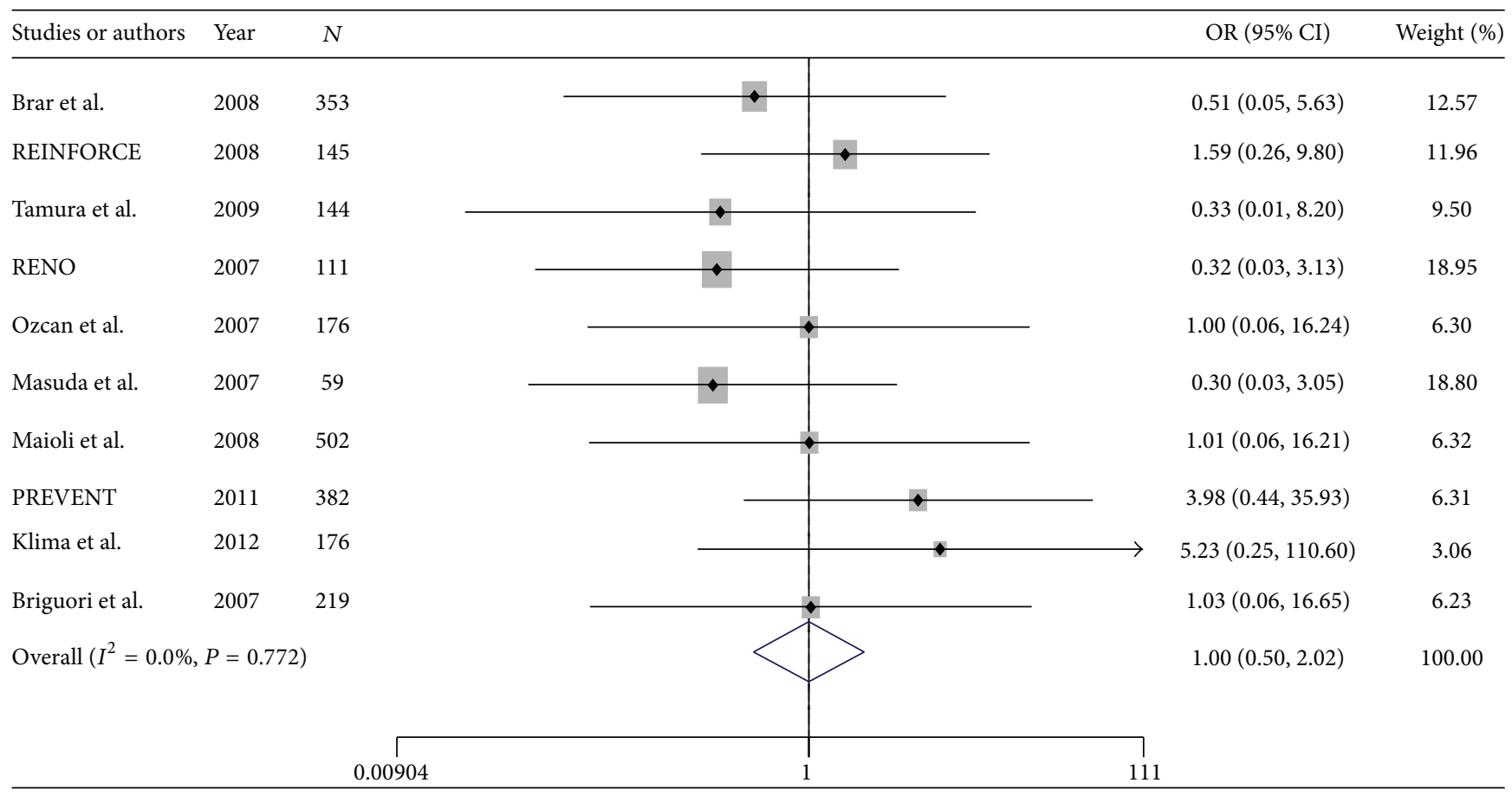

FIGURE 2: Forest plot of odds ratio (OR) for hydration with sodium bicarbonate on incidence of requirement dialysis.

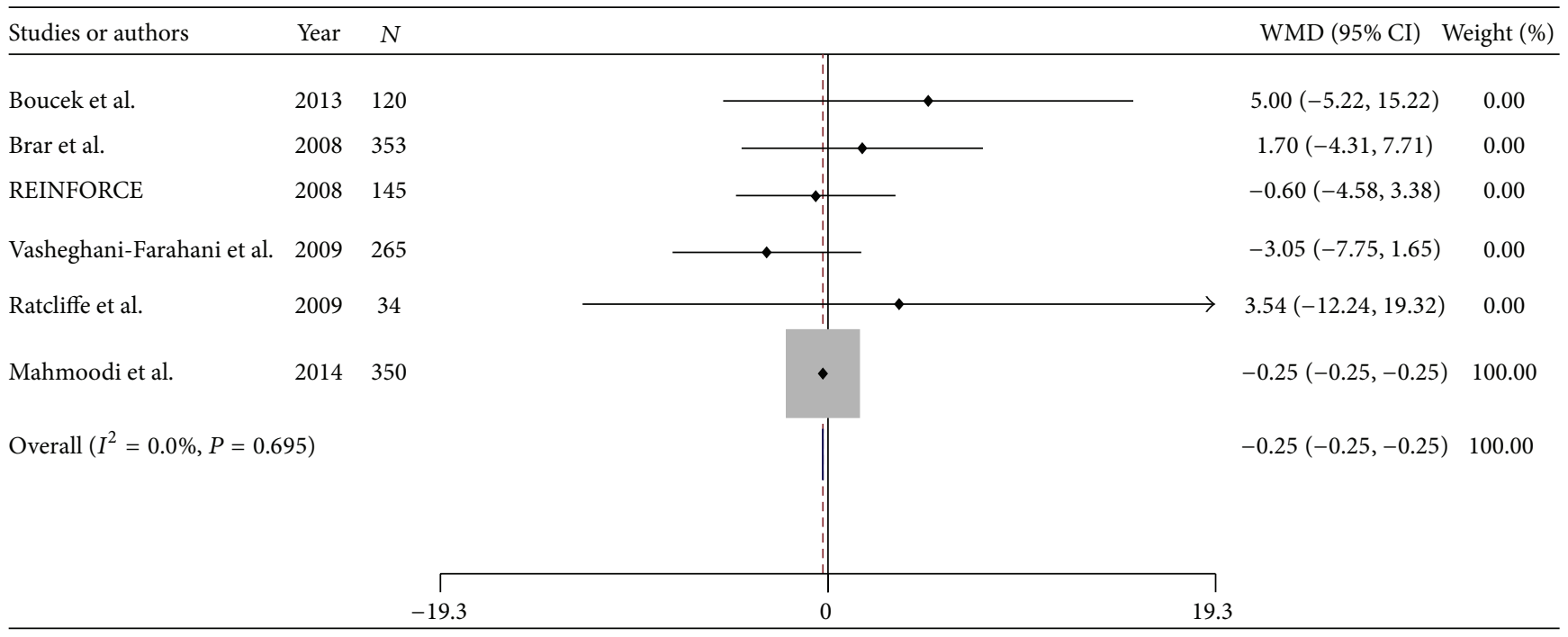

FIGURE 3: Forest plot of weighted mean differences (WMD) for hydration with sodium bicarbonate on mean changes of creatinine.

alone had trend towards reducing the incidence of CIN with an OR of 1.32 (95\% CI: $0.87-1.99 ; P=0.1$ ) using a random model. Significant heterogeneity was observed among the RCTs (chi-squared $=8.42, I^{2}=52.5 \%$ ) (Figure 4 ).

\section{Discussion}

CIN occurs in more than $15 \%$ of patients with chronic renal impairment undergoing diagnostic and therapeutic radiographic procedure $[1,2]$. Approximately $0.5 \%$ to $12 \%$ of these patients require dialysis and longer length of hospital stay, accompanied by worsening of renal function, possibly expediting the evolution toward end stage renal failure [14]. Several protocols have been introduced for prevention of CIN including: periprocedural hydration with isotonic or hypotonic saline and antioxidant compounds such as $\mathrm{N}$ acetyl cysteine (NAC) or ascorbic acid, hemofiltration [2-5]. Regarding the fact that production of free radical oxygen is known as one of the most important pathogenesis of CIN, sodium bicarbonate with its alkali nature might be effective in prevention of $\mathrm{CIN}[9,10]$. The present study revealed that volume expansion with sodium bicarbonate infusion 


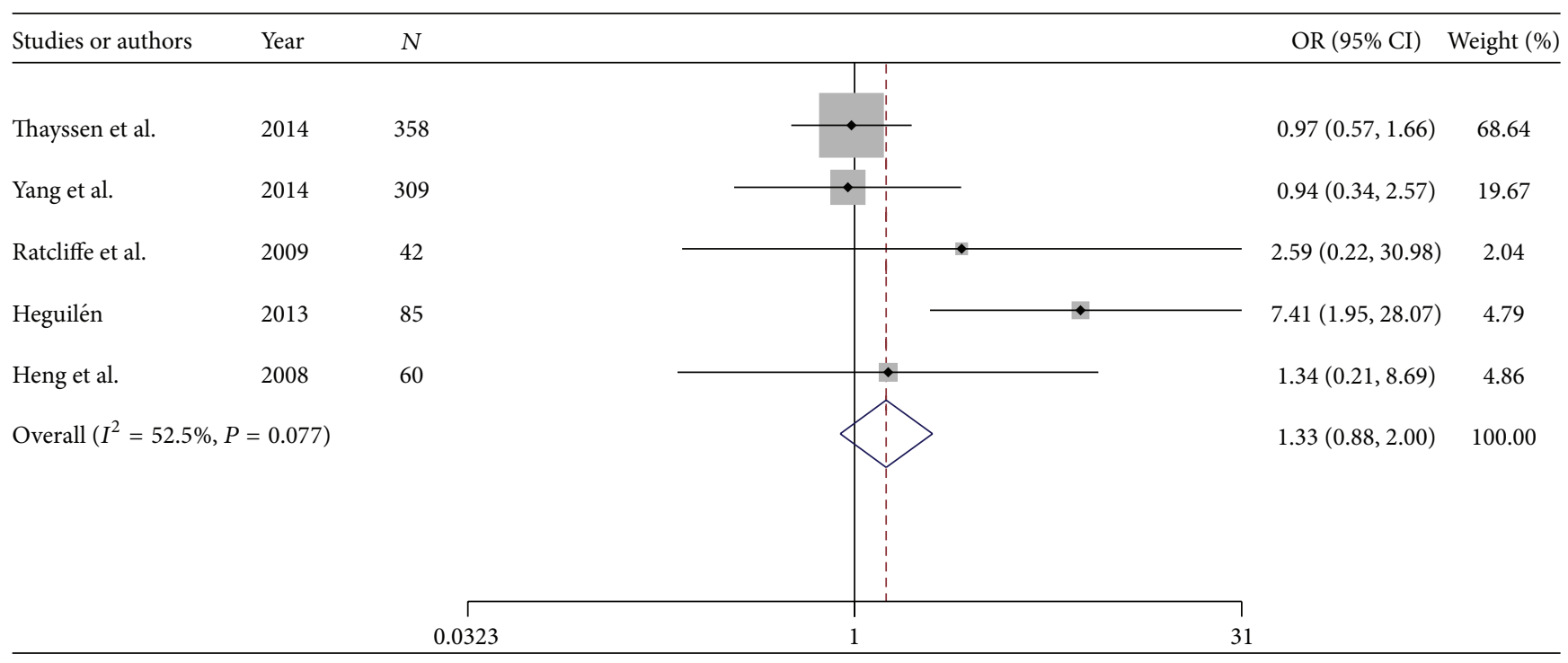

FIGURE 4: Forest plot of odds ratio (OR) for treatment with $\mathrm{N}$-acetyl cysteine and hydration with sodium bicarbonate on contrast-induced nephropathy.

could stimulate dilution of circulating contrast medium and vasoconstrictive mediators and prevent activator of tubuloglomerular feedback and had preventing effect on the incidence of CIN more than normal saline hydration. The results of subgroup analysis indicated that hydration with sodium bicarbonate could reduce the incidence of CIN in both diabetic and nondiabetic patients. Also hydration with sodium bicarbonate showed to be more effective in emergency coronary imaging and high-risk patients as compared with elective coronary imaging. Jang et al. found sodium bicarbonate in remarkable preference to sodium chloride in prevention of CIN. They also reported that patients undergoing emergency imaging would receive more prophylactic effects compared to elective procedures [11]. Possibly acidbase and electrolyte imbalances in high-risk patients undergoing emergency coronary imaging would intensify following toxic effects of radiocontrast and sodium bicarbonate as an antiacid is likely to better control acidic conditions. Antioxidants reduce free radical oxygen, thus being recommended as appropriate therapeutic supplements [12]. The findings of our study suggested that NAC added as an antioxidant supplement to sodium bicarbonate had trend towards reducing the incidence of CIN more than sodium bicarbonate alone. Brown et al. reported that NAC plus sodium bicarbonate hydration could have more protective effect on renal function compared to hydration alone [12]. Subgroup analysis revealed that the least incidence of CIN was when the patients underwent low-osmolality radiocontrast angiography and adequate hydration with sodium bicarbonate plus NAC. Our findings confirmed that iso-osmolality radiocontrast, in comparison with low-osmolality, increased the incidence of CIN; therefore, increase in osmolality intensified acute renal failure. We could assume that the beneficial effects of sodium bicarbonate might be offset by low-osmolar contrast medium volume, which had a more physiologic profile in terms of renal hemodynamics. CIN following angiography could predispose the incidence of renal failure and requirement of dialysis in high-risk patients with diabetic nephropathy and heart failure [3-8]. Despite low incidence of requirement of dialysis, it is of high importance because the patients with this complication generally become prone to morbidity, decrease in quality of life, need for renal transplantation, and mortality. Hydration with sodium bicarbonate had no preference for decreasing hemodialysis and mortality in comparison with sodium chloride. Several previous investigations indicated that clinical endpoint such as renal replacement therapy, heart failure, and mortality were not improved following hydration with sodium bicarbonate versus sodium chloride $[11,12]$. This result may be explained by the fact that the patients who require dialysis in the period of follow-up, in addition to a history of renal disease before angiography, renal cells toxicity is too severe after exposure to radiocontrast leading to crisis of symptoms and incidence of severe CIN [8, 9]. This condition is malignant to such an extent that change in hydration or even addition of drug supplements cannot have protective effects. Acute nephropathy after angiography could increase the length of hospital stay. The current study revealed that hydration with sodium bicarbonate had more trend of decreasing hospitalization compared to sodium chloride. This decrease might be due to reduction in the incidence of CIN and cares related to renal disorders.

A number of studies have found that changes in creatinine levels within 24 to 48 hours after exposure to radiocontrast could be considered as equivalent indicator for new onset CIN [13-18]. Therefore, an increase of $0.5 \mathrm{mg} / \mathrm{dL}$ after angiography demonstrates the incidence of an acute nephropathy. The effects of sodium bicarbonate and sodium chloride on the mean changes of creatinine were not significantly different. Our findings found elevated serum sodium bicarbonate and decreased serum potassium after hydration with sodium bicarbonate. Therefore, in hydration with sodium bicarbonate, patients condition should be monitored 
regarding acid-base balance and changes in electrolytes levels. Finally it is concluded that hydration with sodium bicarbonate could significantly reduce CIN and the length of hospital stay compared to sodium chloride. In addition NAC added as a supplement to sodium bicarbonate could increase prophylactic effects against nephropathy. It is recommended to regularly monitor the patients following hydration with sodium bicarbonate regarding acid-base balance and changes in potassium level in order to avoid complications.

\section{Conflict of Interests}

The authors declare that there is no conflict of interests regarding the publication of this paper.

\section{Authors' Contribution}

Sadegh Ali-Hassan-Sayegh and Seyed Jalil Mirhosseini contributed equally to this review.

\section{Acknowledgment}

The authors would like to thank Dr. Ali Akbar Karimi, Dr. Arezoo Shahidzadeh, and Dr. Fatemeh Haddad for their assistance in writing the paper and Dr. Parisa Mahdavi, Dr. Mahbube Tahernejad, and Dr. Azadeh Shahidzadeh for their assistance in collecting data and statistical analysis.

\section{References}

[1] K. Nash, A. Hafeez, and S. Hou, "Hospital-acquired renal insufficiency," American Journal of Kidney Diseases, vol. 39, no. 5, pp. 930-936, 2002.

[2] C. S. Rihal, S. C. Textor, D. E. Grill et al., "Incidence and prognostic importance of acute renal failure after percutaneous coronary intervention," Circulation, vol. 105, no. 19, pp. 2259$2264,2002$.

[3] B. J. Barrett, "Contrast nephrotoxicity, Journal of the American Society of Nephrology, vol. 5, no. 2, pp. 125-137, 1994.

[4] P. A. McCullough, R. Wolyn, L. L. Rocher, R. N. Levin, and W. W. O’Neill, "Acute renal failure after coronary intervention: incidence, risk factors, and relationship to mortality," The American Journal of Medicine, vol. 103, no. 5, pp. 368-375, 1997.

[5] N. H. Lameire, "Contrast-induced nephropathy-prevention and risk reduction," Nephrology Dialysis Transplantation, vol. 21, no. 1, pp. i11-i23, 2006.

[6] A. J. Taylor, D. Hotchkiss, R. W. Morse, and J. McCabe, "PREPARED: PREParation for angiography in renal dysfunction: a randomized trial of inpatient vs outpatient hydration protocols for cardiac catheterization in mild-to-moderate renal dysfunction," Chest, vol. 114, no. 6, pp. 1570-1574, 1998.

[7] C. Mueller, G. Buerkle, H. J. Buettner et al., "Prevention of contrast media-associated nephropathy: randomized comparison of 2 hydration regimens in 1620 patients undergoing coronary angioplasty," Archives of Internal Medicine, vol. 162, no. 3, pp. 329-336, 2002.

[8] P. A. McCullough, A. Adam, C. R. Becker et al., "Risk prediction of contrast-induced nephropathy," The American Journal of Cardiology, vol. 98, no. 6, pp. 27K-36K, 2006.
[9] H. Sporer, F. Lang, H. Oberleithner, R. Greger, and P. Deetjen, "Inefficacy of bicarbonate infusions on the course of postischaemic acute renal failure in the rat," European Journal of Clinical Investigation, vol. 11, no. 4, pp. 311-315, 1981.

[10] J. L. Atkins, "Effect of sodium bicarbonate preloading on ischemic renal failure," Nephron, vol. 44, no. 1, pp. 70-74, 1986.

[11] J.-S. Jang, H.-Y. Jin, J.-S. Seo et al., "Sodium bicarbonate therapy for the prevention of contrast-induced acute kidney injury-a systematic review and meta-analysis," Circulation Journal, vol. 76, no. 9, pp. 2255-2265, 2012.

[12] J. R. Brown, C. A. Block, D. J. Malenka, G. T. O’Connor, A. C. Schoolwerth, and C. A. Thompson, "Sodium bicarbonate plus $\mathrm{N}$-acetylcysteine prophylaxis. A meta-analysis," JACC: Cardiovascular Interventions, vol. 2, no. 11, pp. 1116-1124, 2009.

[13] P. Boucek, T. Havrdova, O. Oliyarnyk et al., "Prevention of contrast-induced nephropathy in diabetic patients with impaired renal function: a randomized, double blind trial of sodium bicarbonate versus sodium chloride-based hydration," Diabetes Research and Clinical Practice, vol. 101, no. 3, pp. 303308, 2013.

[14] S. S. Brar, A. Y.-J. Shen, M. B. Jorgensen et al., "Sodium bicarbonate vs sodium chloride for the prevention of contrast medium-induced nephropathy in patients undergoing coronary angiography: a randomized trial," The Journal of the American Medical Association, vol. 300, no. 9, pp. 1038-1046, 2008.

[15] E. Adolph, B. Holdt-Lehmann, T. Chatterjee et al., "Renal insufficiency following radiocontrast exposure trial (REINFORCE): a randomized comparison of sodium bicarbonate versus sodium chloride hydration for the prevention of contrastinduced nephropathy," Coronary Artery Disease, vol. 19, no. 6, pp. 413-419, 2008.

[16] A. Vasheghani-Farahani, G. Sadigh, S. E. Kassaian et al., "Sodium bicarbonate plus isotonic saline versus saline for prevention of contrast-induced nephropathy in patients undergoing coronary angiography: a randomized controlled trial," The American Journal of Kidney Diseases, vol. 54, no. 4, pp. 610618, 2009.

[17] J. A. Ratcliffe, P. Thiagarajah, J. Chen et al., "Prevention of contrast-induced nephropathy: a randomized controlled trial of sodium bicarbonate and $\mathrm{N}$-acetylcysteine," International Journal of Angiology, vol. 18, no. 4, pp. 193-197, 2009.

[18] K. Mahmoodi, B. Sohrabi, F. Ilkhchooyi, M. Malaki, M. E. Khaniani, and M. Hemmati, "The efficacy of hydration with normal saline versus hydration with sodium bicarbonate in the prevention of contrast-induced nephropathy," Heart Views, vol. 15, no. 2, pp. 33-36, 2014.

[19] N. Alessandri, L. Lanzi, C. M. Garante et al., "Prevention of acute renal failure post-contrast imaging in cardiology: a randomized study," European Review for Medical and Pharmacological Sciences, vol. 17, pp. 13-21, 2013.

[20] K. Yang, W. Liu, W. Ren, and S. Lv, "Different interventions in preventing contrast-induced nephropathy after percutaneous coronary intervention," International Urology and Nephrology, vol. 46, no. 9, pp. 1801-1807, 2014.

[21] A. Vasheghani-Farahani, G. Sadigh, S. E. Kassaian et al., "Sodium bicarbonate in preventing contrast nephropathy in patients at risk for volume overload: a randomized controlled trial," Journal of Nephrology, vol. 23, no. 2, pp. 216-223, 2010.

[22] P. Thayssen, J. F. Lassen, S. E. Jensen et al., "Prevention of contrast-induced nephropathy with n-acetylcysteine or sodium bicarbonate in patients with ST-segment-myocardial infarction: 
a prospective, randomized, open-labeled trial," Circulation: Cardiovascular Interventions, vol. 7, no. 2, pp. 216-224, 2014.

[23] H. Ueda, T. Yamada, M. Masuda et al., "Prevention of contrastinduced nephropathy by bolus injection of sodium bicarbonate in patients with chronic kidney disease undergoing emergent coronary procedures," The American Journal of Cardiology, vol. 107, no. 8, pp. 1163-1167, 2011.

[24] A. Tamura, Y. Goto, K. Miyamoto et al., "Efficacy of single-bolus administration of sodium bicarbonate to prevent contrastinduced nephropathy in patients with mild renal insufficiency undergoing an elective coronary procedure," The American Journal of Cardiology, vol. 104, no. 7, pp. 921-925, 2009.

[25] L. Shavit, R. Korenfeld, M. Lifschitz, A. Butnaru, and I. Slotki, "Sodium bicarbonate versus sodium chloride and oral $N$-acetylcysteine for the prevention of contrast-induced nephropathy in advanced chronic kidney disease," Journal of Interventional Cardiology, vol. 22, no. 6, pp. 556-563, 2009.

[26] A. Recio-Mayoral, M. Chaparro, B. Prado et al., "The renoprotective effect of hydration with sodium bicarbonate plus $\mathrm{N}$ acetylcysteine in patients undergoing emergency percutaneous coronary intervention: the RENO Study," Journal of the American College of Cardiology, vol. 49, no. 12, pp. 1283-1288, 2007.

[27] M. Pakfetrat, M. H. Nikoo, L. Malekmakan et al., "A comparison of sodium bicarbonate infusion versus normal saline infusion and its combination with oral acetazolamide for prevention of contrast-induced nephropathy: a randomized, double-blind trial," International Urology and Nephrology, vol. 41, no. 3, pp. 629-634, 2009.

[28] E. E. Ozcan, S. Guneri, B. Akdeniz et al., "Sodium bicarbonate, $\mathrm{N}$-acetylcysteine, and saline for prevention of radiocontrastinduced nephropathy. A comparison of 3 regimens for protecting contrast-induced nephropathy in patients undergoing coronary procedures. A single-center prospective controlled trial," American Heart Journal, vol. 154, no. 3, pp. 539-544, 2007.

[29] M. Motohiro, H. Kamihata, S. Tsujimoto et al., "A new protocol using sodium bicarbonate for the prevention of contrastinduced nephropathy in patients undergoing coronary angiography," American Journal of Cardiology, vol. 107, no. 11, pp. 16041608, 2011.

[30] G. J. Merten, W. P. Burgess, L. V. Gray et al., "Prevention of contrast-induced nephropathy with sodium bicarbonate: a randomized controlled trial," The Journal of the American Medical Association, vol. 291, no. 19, pp. 2328-2334, 2004.

[31] M. Masuda, T. Yamada, T. Mine et al., "Comparison of usefulness of sodium bicarbonate versus sodium chloride to prevent contrast-induced nephropathy in patients undergoing an emergent coronary procedure," The American Journal of Cardiology, vol. 100, no. 5, pp. 781-786, 2007.

[32] M. Maioli, A. Toso, M. Leoncini et al., "Sodium bicarbonate versus saline for the prevention of contrast-induced nephropathy in patients with renal dysfunction undergoing coronary angiography or intervention," Journal of the American College of Cardiology, vol. 52, no. 8, pp. 599-604, 2008.

[33] S.-W. Lee, W.-J. Kim, Y.-H. Kim et al., "Preventive strategies of renal insufficiency in patients with diabetes undergoing intervention or arteriography (the PREVENT Trial)," American Journal of Cardiology, vol. 107, no. 10, pp. 1447-1452, 2011.

[34] F. Koc, K. Ozdemir, F. Altunkas et al., "Sodium bicarbonate versus isotonic saline for the prevention of contrastinduced nephropathy in patients with diabetes mellitus undergoing coronary angiography and/or intervention: a multicenter prospective randomized study," Journal of Investigative Medicine, vol. 61, no. 5, pp. 872-877, 2013.
[35] T. Klima, A. Christ, I. Marana et al., "Sodium chloride vs. sodium bicarbonate for the prevention of contrast mediuminduced nephropathy: a randomized controlled trial," European Heart Journal, vol. 33, no. 16, pp. 2071-2079, 2012.

[36] R. M. Heguilén, A. A. Liste, M. Payaslian, M. G. Ortemberg, L. M. Albarracín, and A. R. Bernasconi, "N-acethyl-cysteine reduces the occurrence of contrast-induced acute kidney injury in patients with renal dysfunction: a single-center randomized controlled trial," Clinical and Experimental Nephrology, vol. 17, no. 3, pp. 396-404, 2013.

[37] A. M. Hafiz, M. F. Jan, N. Mori et al., "Prevention of contrastinduced acute kidney injury in patients with stable chronic renal disease undergoing elective percutaneous coronary and peripheral interventions: randomized comparison of two preventive strategies," Catheterization and Cardiovascular Interventions, vol. 79, no. 6, pp. 929-937, 2012.

[38] V. O. Gomes, R. Lasevitch, V. C. Lima et al., "Hydration with sodium bicarbonate does not prevent contrast nephropathy: a multicenter clinical trial," Arquivos Brasileiros de Cardiologia, vol. 99, no. 6, pp. 1129-1134, 2012.

[39] D. Castini, S. Lucreziotti, L. Bosotti et al., "Prevention of contrast-induced nephropathy: a single center randomized study," Clinical Cardiology, vol. 33, no. 3, pp. E63-E68, 2010.

[40] C. Briguori, F. Airoldi, D. D’Andrea et al., "Renal insufficiency following contrast media administration trial (REMEDIAL): a randomized comparison of 3 preventive strategies," Circulation, vol. 115, no. 10, pp. 1211-1217, 2007.

[41] A. E. Heng, E. Cellarier, B. Aublet-Cuvelier et al., "Is treatment with $\mathrm{N}$-acetylcysteine to prevent contrast-induced nephropathy when using bicarbonate hydration out of date?" Clinical Nephrology, vol. 70, no. 6, pp. 475-484, 2008. 


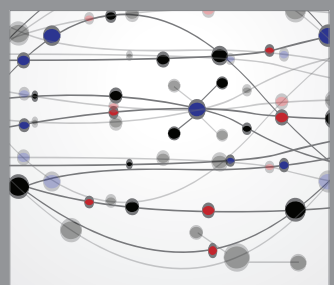

The Scientific World Journal
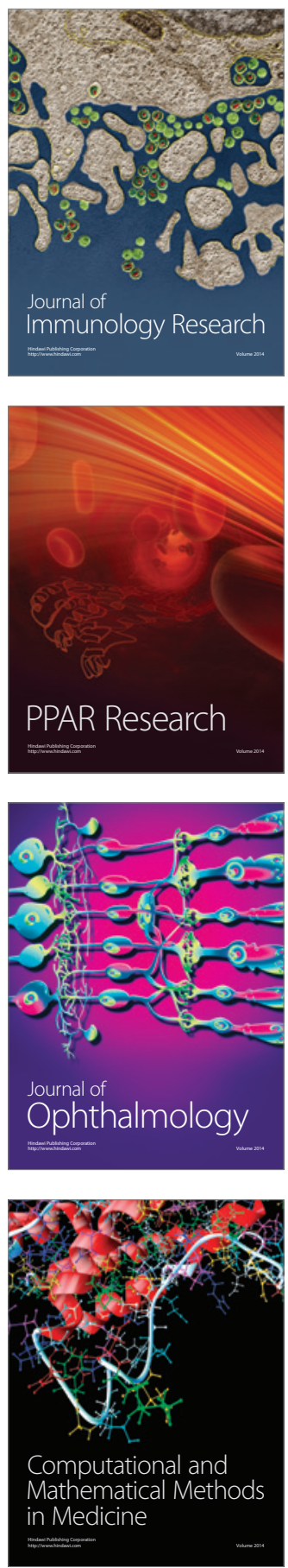

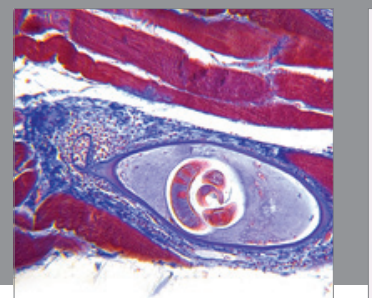

Gastroenterology

Research and Practice
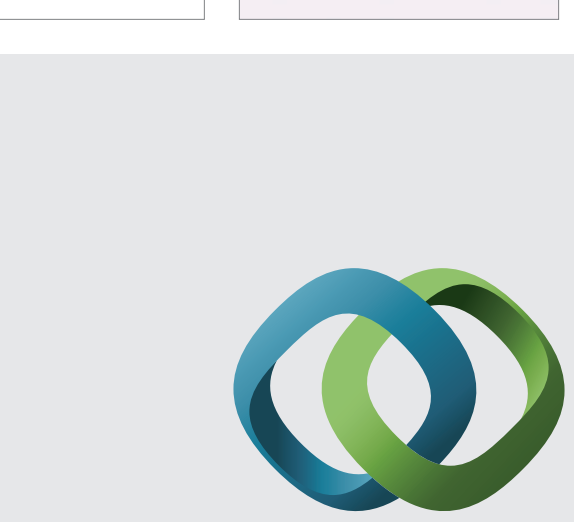

\section{Hindawi}

Submit your manuscripts at

http://www.hindawi.com
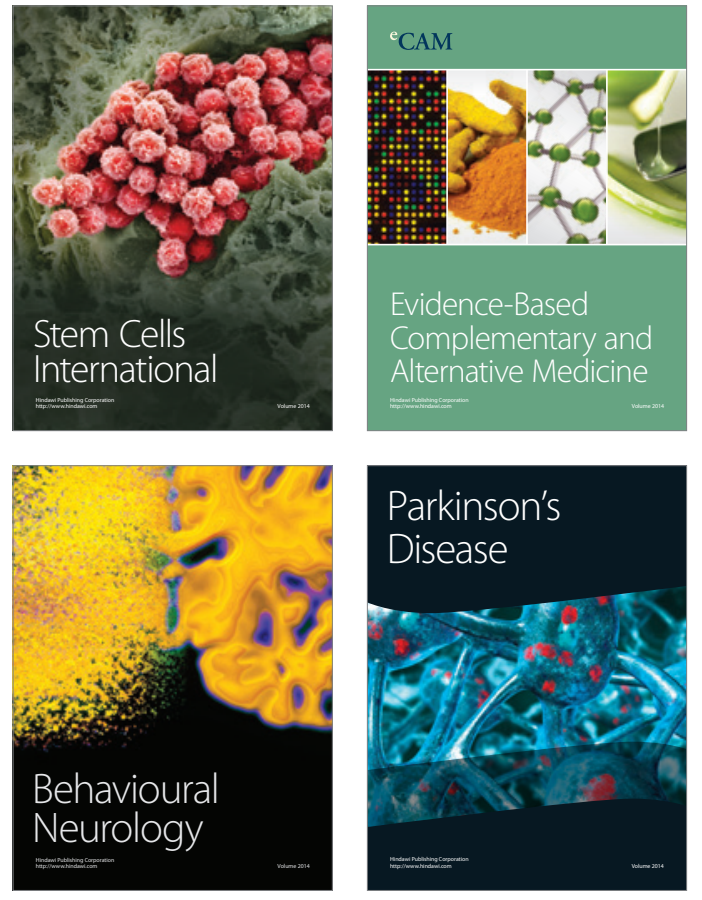
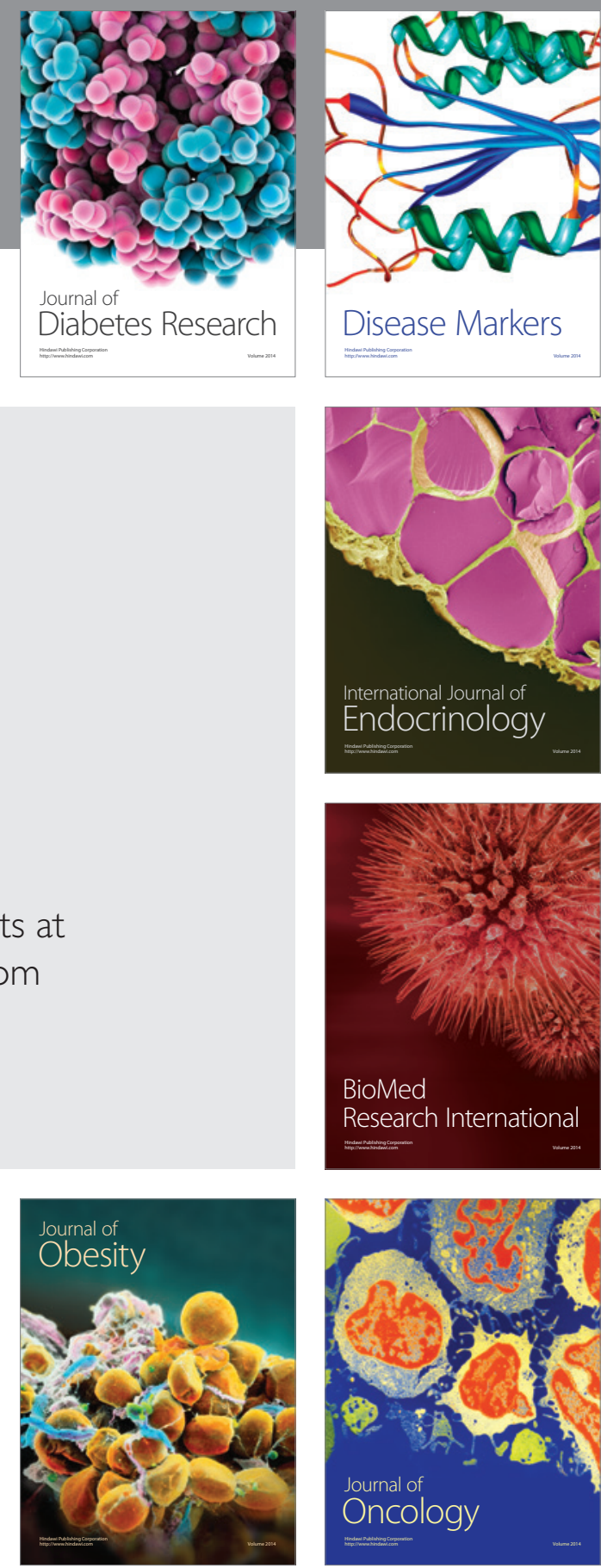

Disease Markers
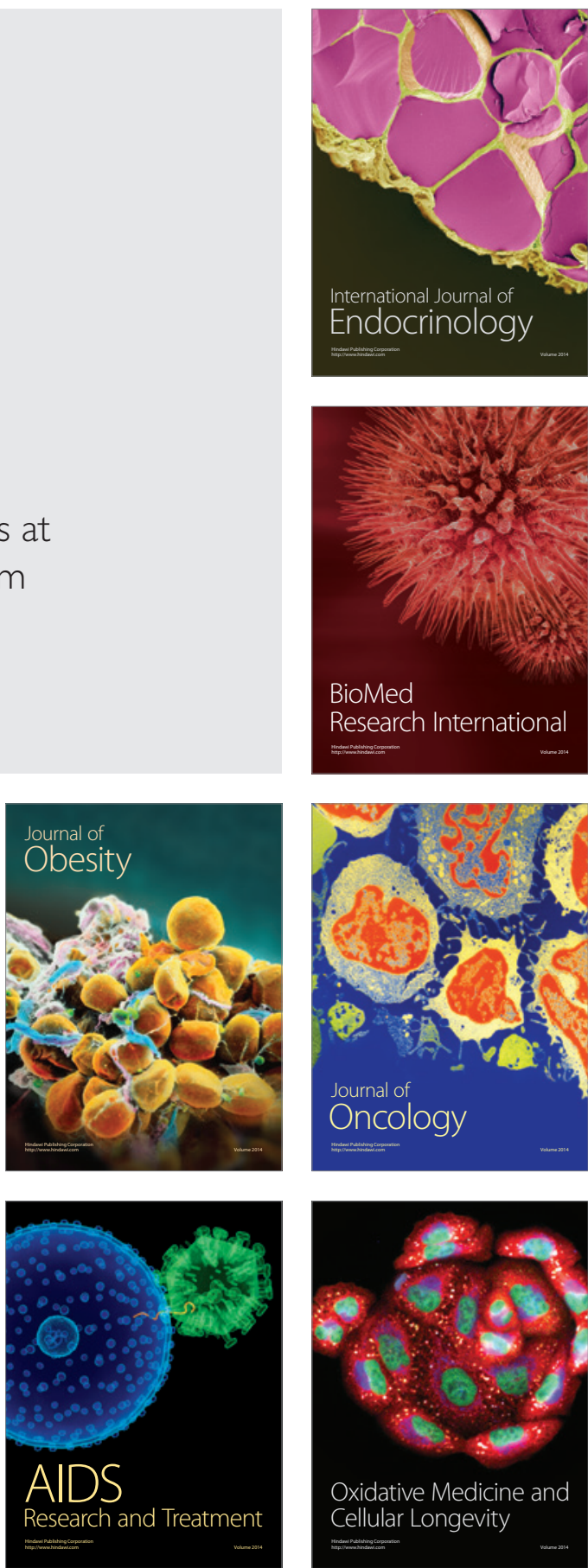